\title{
REGULARIZED RECONSTRUCTION OF GRID SYSTEM FOR TRADITIONAL CHINESE TIMBER STRUCTURE BUILDING IN HBIM
}

\author{
J. Yang ${ }^{1}$, X. Wang ${ }^{1}$, C. Wu ${ }^{1, *}$, C. Bai ${ }^{2}$ \\ ${ }^{1}$ School of Architecture, Tianjin University, 92 Weijin Rd, Nankai District, Tianjin, P. R. China - untiedsoul@163.com; \\ wangxi88love@qq.com; wucong@tju.edu.cn \\ ${ }^{2}$ School of Civil Engineering, Tianjin University, 92 Weijin Rd, Nankai District, Tianjin, P. R. China - Babybcj@ sina.com
}

\section{Commission II, WG II/8}

KEY WORDS: Traditional Chinese Timber Structure Building, Grid System, Regularity, Algorithm Rebuild, Grasshopper, HBIM

\begin{abstract}
:
The grid system of traditional Chinese timber structure building is generally rectangular or in other regular geometric shapes. Due to construction errors, building deformation and other reasons, the actual grid system obtained by laser 3D scanning technology is usually not in regular shape. The purpose of HBIM is to favor regularity, and it is necessary to carry out regularized reconstruction on the grid system. By reconstruction of the grid using genetic algorithm in Grasshopper, feasible regularized HBIM models can be obtained.
\end{abstract}

\section{BACKGOUND}

The traditional Chinese timber structure is a frame structure composed of columns and beams. The column plays a bearing role $(\mathrm{Li}, 2015)$. They are arranged in a certain order to form a rectangular (or other regular geometric shapes) grid (Di, 2009).

After scanning the traditional Chinese wooden structure using 3D laser scanning technology, point cloud data is obtained. In the point cloud, make a slice of the root position of the column, the actual core of each column can be obtained. Due to construction errors, building deformation and other reasons, connecting the actual cores of columns, the actual grid we get will definitely not be a very regular rectangular (or other geometric shape) grid. That is: the actual cores of columns are often not in a straight line. If connected together, usually we get a polyline.

Therefore, there is a problem which need to be solved. In HBIM, should we make models according to the actual grid system or regularize reconstruction in the grid system?

If modeled according to the actual grid system, then all the columns and beams of the building will be skewed, and the next modeling process will not be possible. In fact, to do a specific documentation work, one has to keep balance between opposite poles: regularity and differentiation according to the goals and specific needs of the project, for the purpose of HBIM is to make an index frame model.

HBIM model should be regarded as a sustainable frame of index for heritage information management, an archetypal or ideal model which is built with a set of "sampling sizes," representing specific form, material, style of the building while ignoring detailed, subtle differentiation: deformations, defectives or irregularities. Based on this framework, other properties, information and related analysis, calculation could be searched, tagged, indexed, attached or externally linked, and updated. HBIM should focus more on regularity. Reconstruct the grid by genetic algorithm in Grasshopper so a feasible regularized HBIM model can be obtained. Therefore, in HBIM, it is necessary to carry out regularized reconstruction on the grid system of traditional Chinese timber structure building (Wang, $\mathrm{Wu}$, and Han, 2016).

\section{METHODOLOGY}

\subsection{Error Calculation}

Assuming that the theoretical position of cores of columns (the center position of column) is $\left(x_{0}, y_{0}\right)$. It can be considered that through this theoretical position, a regular column-column relationship (such as a straight line, a rectangle, an octagon, a circle, etc.) can be formed (Bai, 2007).

After the measured position of the cores of column is obtained, which is $(x, y)$, the displacemFent between the measured position and the theoretical position is:

$$
\left\{\begin{array}{l}
\Delta x=x-x_{0} \\
\Delta y=y-y_{0}
\end{array}\right.
$$

Mean square error of a point is: (Directional point deviation)

$$
e=\sqrt{\Delta x^{2}+\Delta y^{2}}
$$

Offset angle is:

$$
\alpha=\arctan \frac{\Delta y}{\Delta x}
$$

The point error is represented by the error ellipse as shown in the Figure 1.

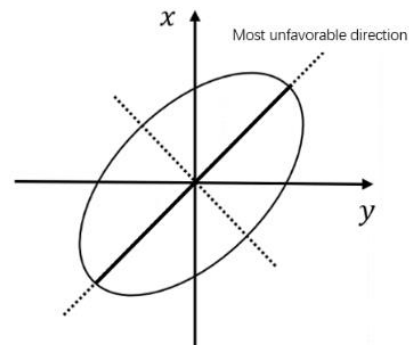

Figure 1. error ellipse

\footnotetext{
* Corresponding author, this paper is supported by National Natural Science Foundation of China:(project NO. 51878440)
} 
To calculate the error between the measured position and the theoretical position, the following parts should be considered:

The manufacturing error of the beam and the purlin (Because the length of the beam and the purlin is directly related to the distance between the columns). Referring the Quality Inspection Evaluation Standards of Ancient Building Construction, the admissible error of the length of the beam and the purlin is $\pm 1 / 2000$. Set the maximum length of the beam to $10 \mathrm{~m}$, the error (under the most adverse conditions) is:

$$
e_{1}=10 \mathrm{~m} \times \frac{1}{2000}= \pm 5 \mathrm{~mm}
$$

1. The construction error of the beam and the purlin. Referring the Quality Inspection Evaluation Standards of Ancient Building Construction, the allowable value of this error is:

$$
e_{2}=20 \mathrm{~m} \times \frac{1.5}{1000}= \pm 30 \mathrm{~mm}
$$

2. The component deformation error. Since this error has little effect on the position of the column, it can be ignored.

3. The measurement error. The measurement accuracy is usually set according to the scale of the drawing. And single building (single plane) usually has a scale of 1:100. So, the measurement error can be estimated as:

$$
e_{3}=0.1 \mathrm{~mm} \times 100= \pm 10 \mathrm{~mm}
$$

In summary, the resultant error is:

$e= \pm \sqrt{e_{1}^{2}+e_{2}^{2}+e_{3}^{2}}= \pm \sqrt{5^{2}+30^{2}+10^{2}}= \pm 32 \mathrm{~mm}$

Taking into account the state of construction technology in ancient China, we have to double this error, which is $\pm 64 \mathrm{~mm}$.

\subsection{Typical Example}

Take Jingfu Palace located in the Forbidden City in Beijing as an example (Figure 2)

Jingfu Palace is a single-storey wood structure building with grid system close to square. As shown in the Figure 3 or Figure 4, it has 48 wooden columns.

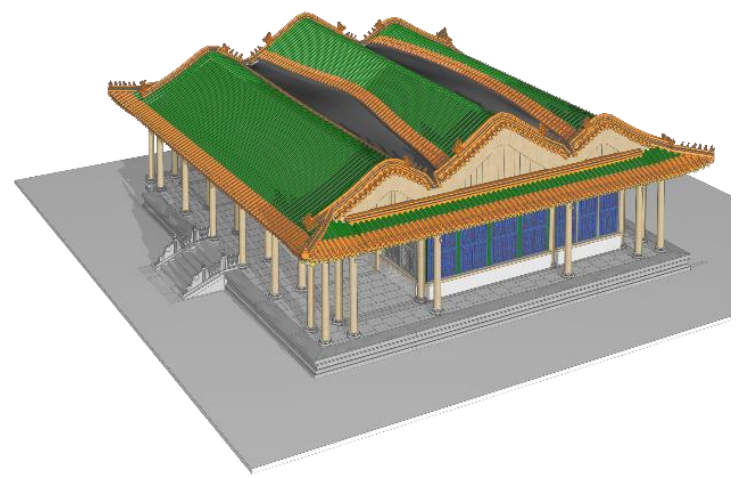

Figure 2. Jingfu Palace

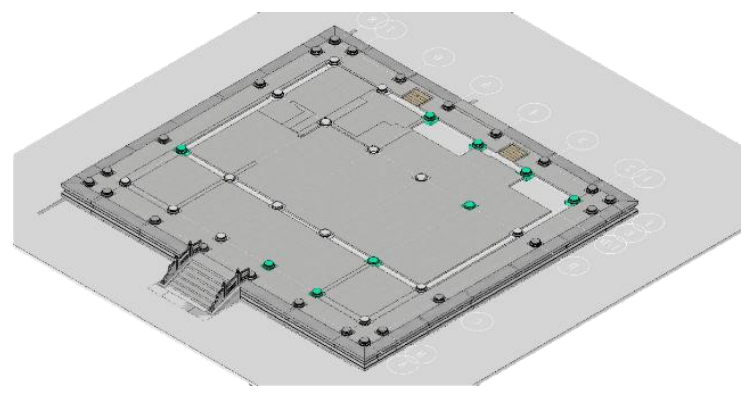

Figure 3. the base of Jingfu Palace

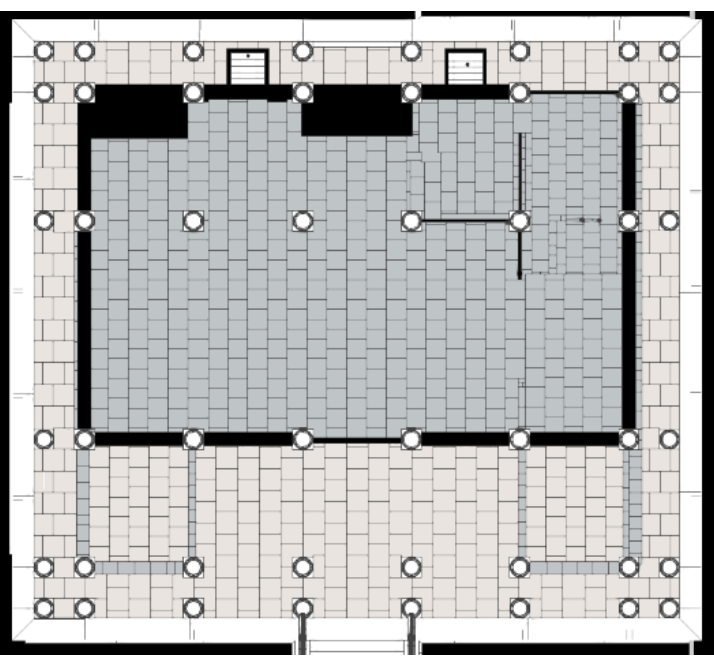

Figure 4. the flat of Jingfu Palace

1. After scanning the traditional Chinese wooden structure using 3D laser scanning technology (Bai, and $\mathrm{Wu}, 2012$ ), point cloud data is obtained. In the point cloud, make a slice of the root position of the column (Bai, Wu, and Zhang, 2013). By fitting, the actual cores of each column can be obtained. After extraction, they are exported to the actual grid system model. (Figure 5)

Figure 5. the actual grid system model of Jingfu Palace

1. Import the actual grid system model into the Grasshopper software. Preset grid is a square grid, using genetic algorithm, adjust the actual core model automatically. So, a reconstruction grid system model is obtained. (Figure 6) 


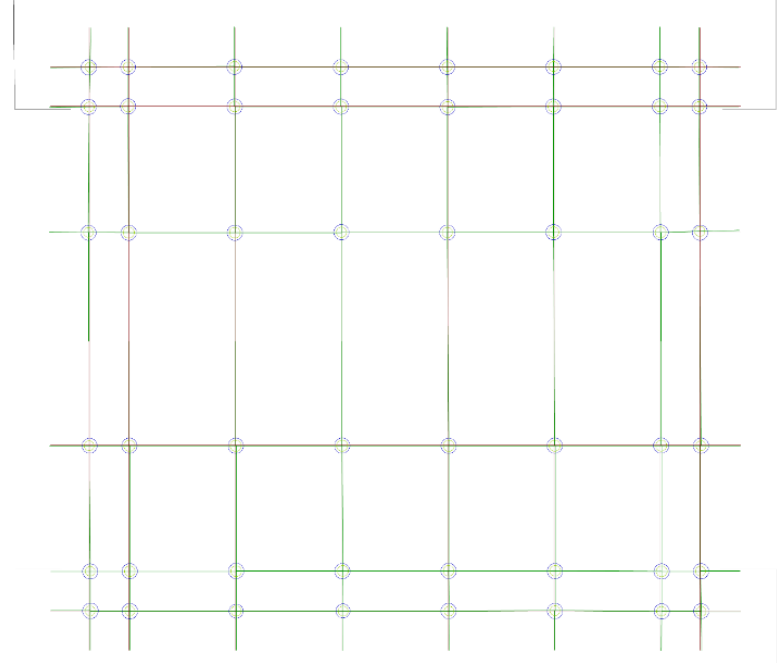

Figure 6. reconstruction grid system of Jingfu Palace

2. Relate the reconstructed the column core with the original column core, the direction and distance relationship are shown below. The difference is between 9.93 and 46.89 with an average of 30.92 in millimeters.(Table 1) In this result, there is no value greater than 64 . It can be considered that the reconstruction grid system is reliable. Applying the grid data in a BIM software. (Figure 7)

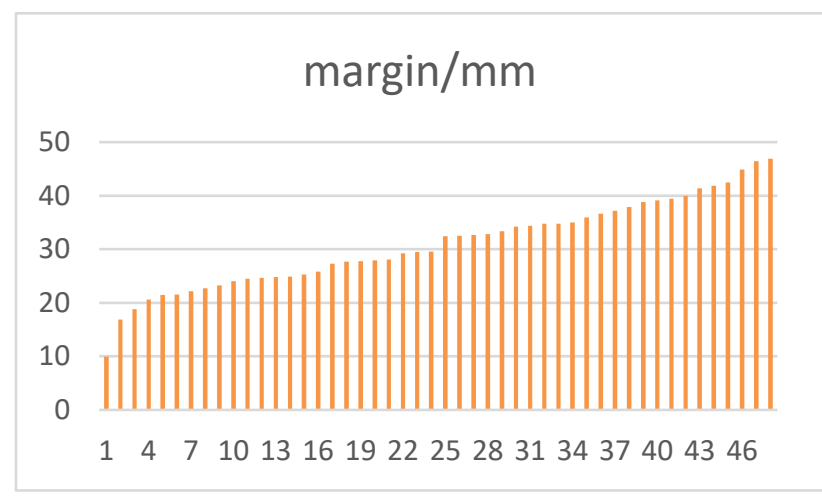

Table 1. the grid data of Jingfu palace

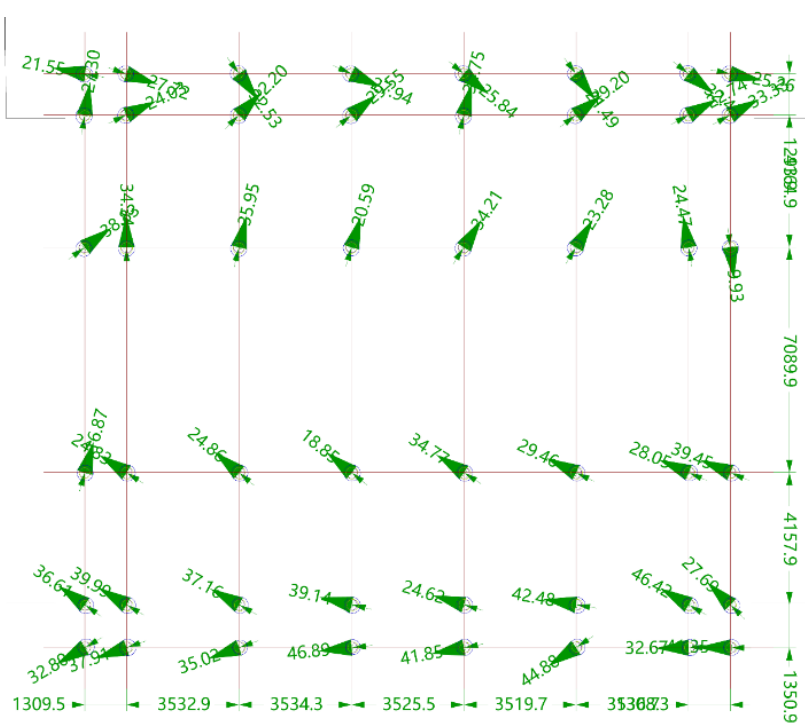

Figure 7. the process of reconstruction of Jingfu Palace
3. If a value greater than 64 occurs during the reconstruction of other building grids, we believe that the columns deviate too much and are abnormal samples. Their existence may interfere in the calculation process of the reconstruction of building grid. So, remove the values greater than 50 and repeat step (3) for the remaining samples.

\subsection{Others Examples}

1. Some buildings have simple grid systems, like LuBan Shrine, a traditional Chinese architecture located in Jizhou District, Tianjin.(Figure 8)

2. LuBan Shrine is a single-storey wooden building. Its grid system is close to a rectangle. It has 14 columns (Figure 9), of which only 10 can be seen. In this case, we believe that the grid system is only determined by the visible column positions. The reconstruction process is shown in Figure 10.

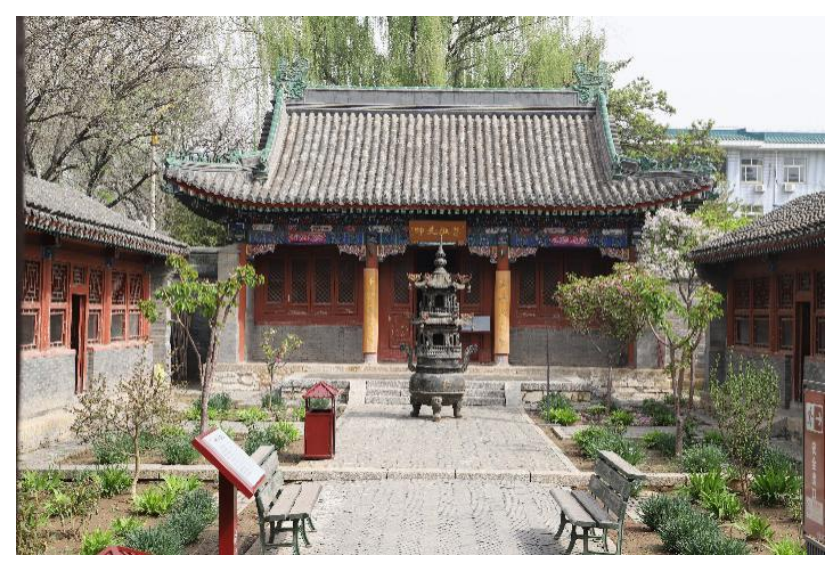

Figure 8. LuBanShrine

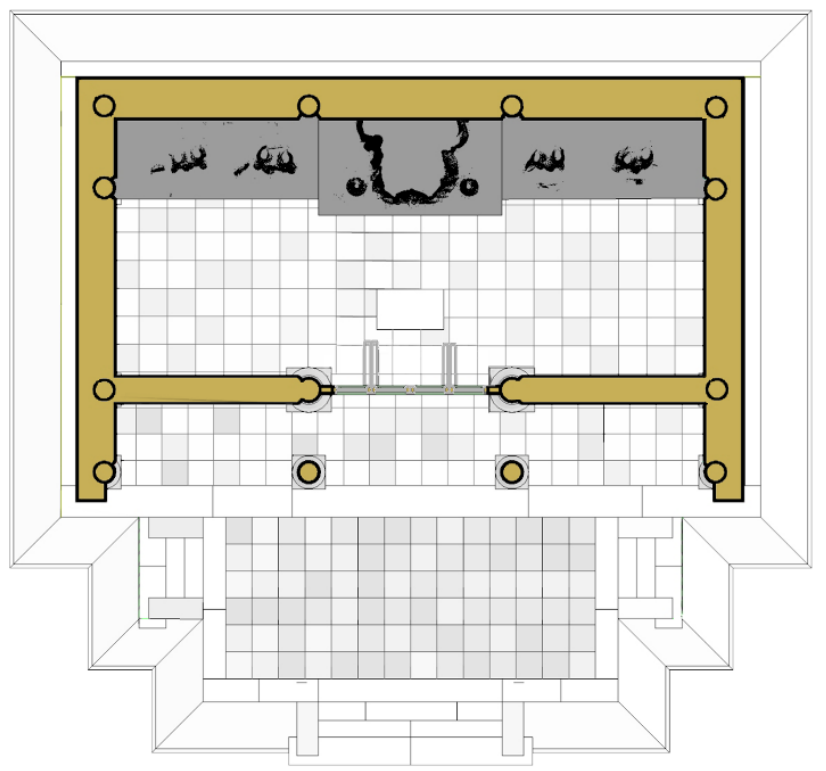

Figure 9. the flat of LuBanShrine 


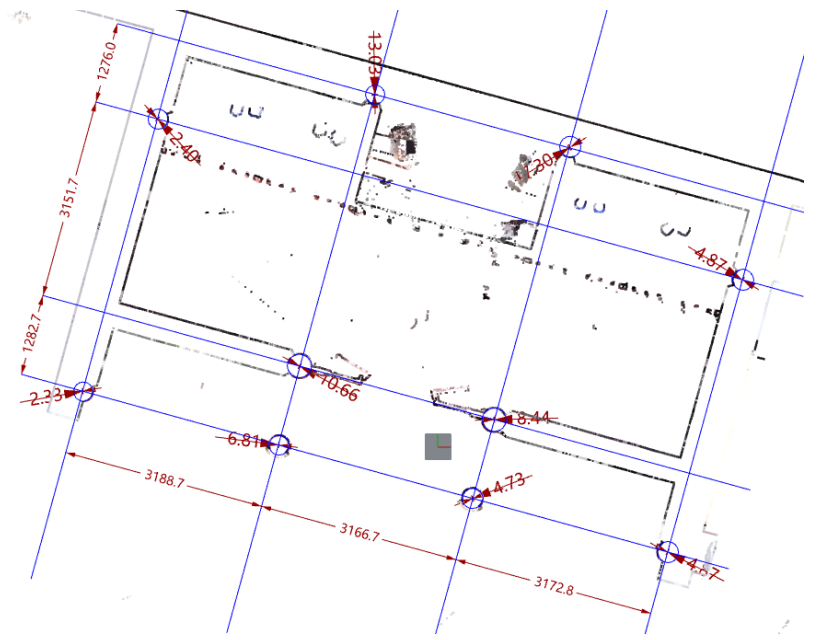

Figure 10. the process of reconstruction of LuBanShrine

1. For multi-storey buildings, take Guanghua Pavilion (Figure 11) in Jiayu Guan in Gansu as an example.

2. For multi-storey pavilions: First, rebuild the grid systems of each layer separately. Then, calculate the centroid of each layer of the grid system. Finally, overlay the grid systems of each layer. During the superposition process, the centroids of each layer of the column are kept coincident. (Figure 12 to Figure 16)

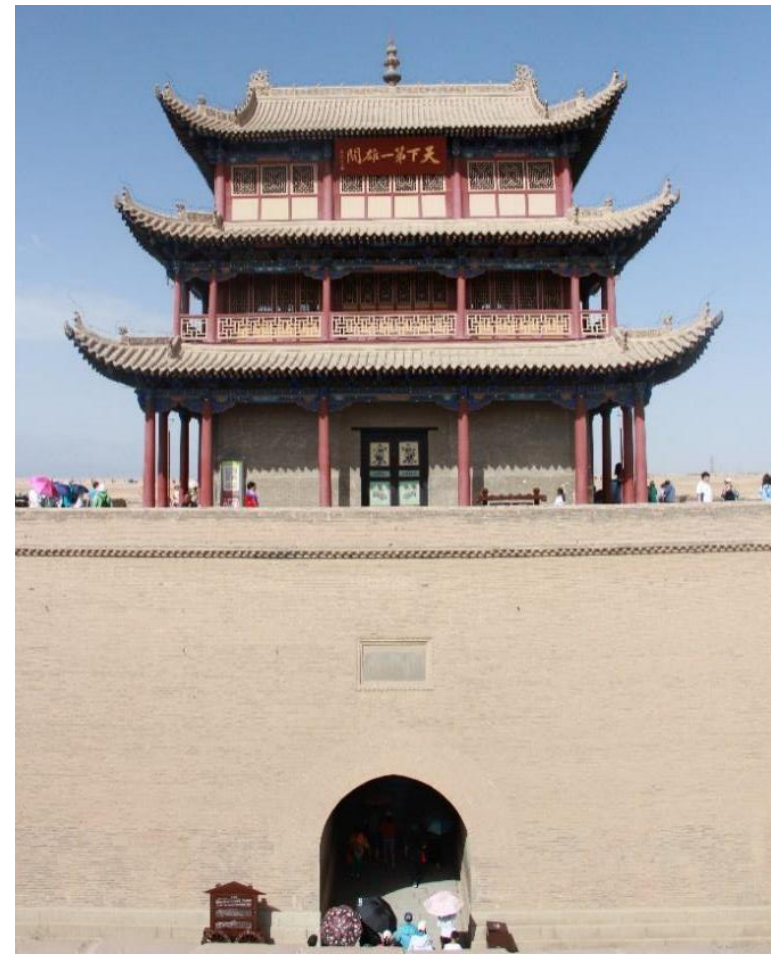

Figure 11. Guanghua Pavilion

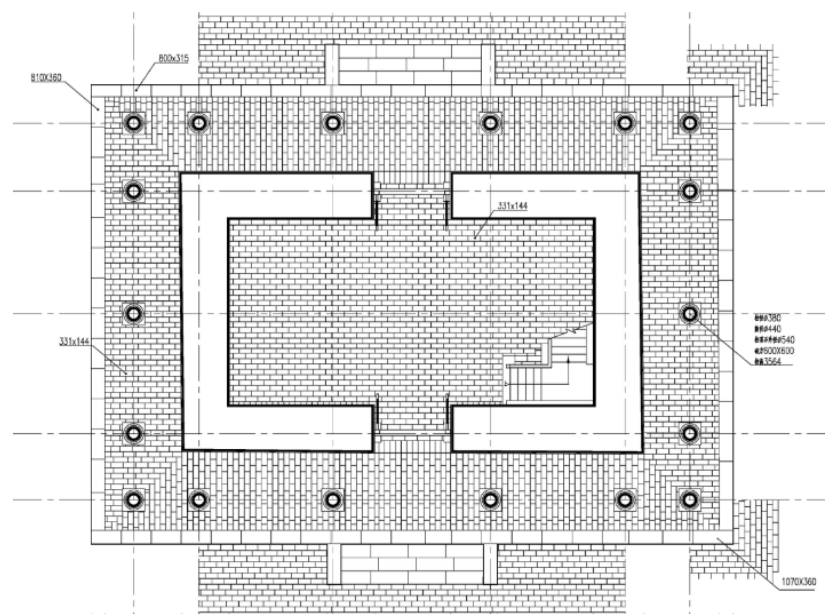

Figure 12. the plan of Guanghua Pavilion
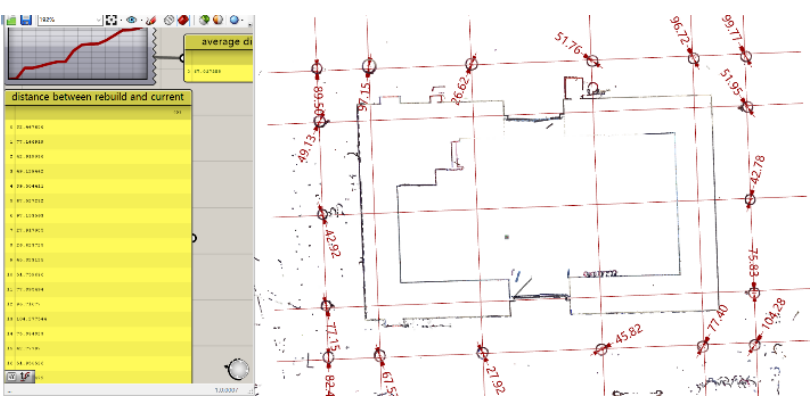

Figure 13. the grid system of the first floor
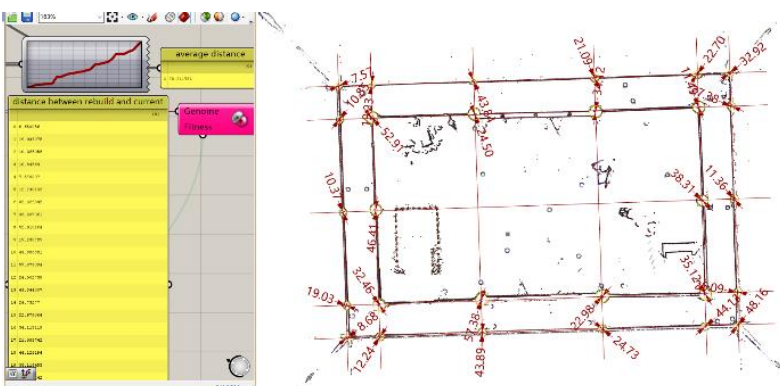

Figure 144. the grid system of the second floor
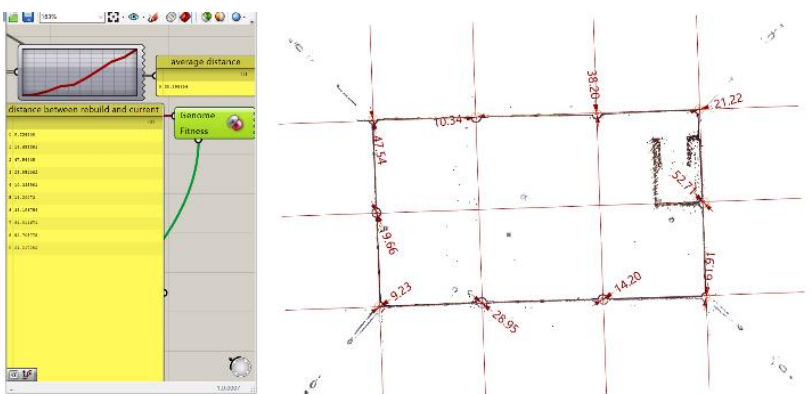

Figure 15. the grid system of the third floor 


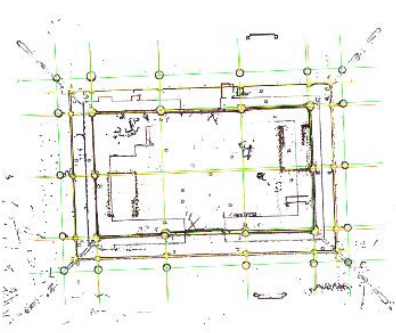

Figure 15. result after superposition

\section{SIGNIFICANCE}

1. The reconstruction process of the grid system is completed by the computer, automatically solved using genetic algorithm, not artificial calculations, it can minimize manual errors, and the data obtained is more accurate;

2. After the algorithm is built, only change the input to get the output. It has a certain versatility, can be applied to other buildings with similar plans.

3. In the past mapping process, the determination of the grid system of different buildings requires repeated repetition of the same process. Therefore, this algorithm model also greatly saves people's time and effort.

\section{CONCLUSION}

The determination of the grid system bases on HBIM modeling process. HBIM is biased towards regularization, and its purpose is to make an index frame model. Therefore, it is necessary to regularize reconstruction of the grid system before modeling. Reconstruct the grid by genetic algorithm in Grasshopper. It is confirmed by examples that this process is feasible. At the same time, it has high accuracy and certain versatility. Next, we will also rebuild the grid system for architectures of other shapes (circle, octagon .etc). Inevitably, this article has many omissions and hopes to get corrections.

\section{ACKNOWLEDGEMENTS}

This paper is partially supported by following institution: the Palace Museum, China; Jiayuguan Academy of Silk Road (the Great Wall) Culture, Gansu; Cultural Heritage Administration of Jizhou District, Tianjin.

\section{REFERENCE}

Bai, C., 2007. Research on application of laser 3D scanning technology in ancient architecture measuring \& relative issues, Tianjin University.

Bai, C., and Wu, C., 2012. Study on the core questions of the application of 3D laser scanning to metric survey of historic buildings. Bulletin of Surveying and Mapping, 2012(1), pp. 3638 .

Bai, C., Wu, C., and Zhang, L., 2013. Application of the whole series of 3D laser scanning technology to cultural relics and archeological surveying. Journal of Tianjin University (Social Sciences), 15(5), pp. 436-439.
Di, Y., 2009. Research on Standardization System of Architectural Heritage Documentation in China. Tianjin University.

Li, J., 2015. Study on the History of Chinese Architectural Heritage Surveying and Mapping. Tianjin University.

Wang, W., Wu, C., and Han, T., 2016. Discussion on heritage recording and authenticity. The Architect, 2016(2), pp. 73-76. 